\title{
LONG-TERM EFFECTS OF A NATIONWIDE CONTROL PROGRAM ON THE SEROPOSITIVITY FOR TRYPANOSOMA CRUZI INFECTION IN YOUNG MEN FROM ARGENTINA
}

\author{
ELSA L. SEGURA, ESTELA N. CURA, SERGIO A. SOSA ESTANI, JORGE ANDRADE, JUAN C. LANSETTI, \\ ANA M. DE RISSIO, ADA CAMPANINI, SONIA B. BLANCO, RICARDO E. GÜRTLER, AND MANUEL ALVAREZ \\ Administración Nacional de Laboratorios e Institutos de Salud (ANLIS) Dr. Carlos G. Malbrán, Buenos Aires, Argentina; \\ Centro Nacional de Control de Calidad, Centro Nacional de Diagnóstico e Investigación en Endemoepidemias (CENDIE), \\ Instituto Nacional de Producción de Biológicos,; Secretaría de Movilización, Ministerio de Salud y Acción Social de la Nación, \\ Buenos Aires, Argentina; Servicio Nacional de Chagas, Ministerio de Salud y Acción Social de la Nación, Córdoba, Argentina; \\ Instituto Nacional de Parasitología Dr. Mario Fatala Chabén, ANLIS Dr. Carlos G. Malbrán, Buenos Aires, Argentina; \\ Facultad de Ciencias Exactas y Naturales, Universidad de Buenos Aires, Buenos Aires, Argentina
}

\begin{abstract}
Unselected nationwide cohorts of Argentine men 18 years of age summoned for military service were tested for antibodies to Trypanosoma cruzi each year from 1981 to 1993. After an initial screening using indirect hemagglutination test, the positive sera were retested by titrated indirect hemagglutination and immunofluorescence antibody tests at 39 laboratories or at the national reference center in Buenos Aires. Nearly 1.8 million men were examined for $T$. cruzi antibodies using the same standardized procedures under a quality assurance program. The prevalence of seropositivity for T. cruzi decreased significantly from $5.8 \%$ in 1981 to $1.9 \%$ in 1993 , but the decrease was not homogeneous among provinces within each region or constant over time. Prior to the nationwide control campaign initiated in 1961-1962, 15 provinces had high $(>20 \%)$ percentages of houses with domiciliary infestation by Triatoma infestans bugs, which decreased to nine provinces in 1982, and four provinces in 1992. The observed decrease in the prevalence of seropositivity for $T$. cruzi may be mostly attributed to the spraying with insecticides to eliminate the domiciliary populations of Triatoma infestans. The lack of a sustainable triatomine surveillance program set a limit to the decrease of seropositivity rates and prompted a revised strategy based on community participation.
\end{abstract}

\section{INTRODUCTION}

Trypanosoma cruzi, the causative agent of Chagas' disease, is mainly transmitted by triatomine bugs, but also from mother to child, by blood transfusion, and organ transplantation. Approximately 16-18 million people in the Americas, ${ }^{1}$ including 2.3 million people from Argentina, ${ }^{2}$ were estimated to be infected with T. cruzi. In Argentina, Triatoma infestans is the main or only domiciliary vector of $T$. cruzi; historically, it had a wide distribution range from the northern border with Bolivia and Paraguay to $45^{\circ} 35^{\prime} \mathrm{S}$ in the province of Chubut, thus excluding Santa Cruz and Tierra del Fuego. ${ }^{3}$ Since 1992, Triatoma infestans has been the subject of a regional elimination program ('Iniciativa del Cono Sur') based mostly on house sprayings with residual insecticides. $^{4}$

Serologic surveillance of rural residents after insecticidal campaigns have documented a rapid decrease in the rates of seropositivity for $T$. cruzi. . $^{5,6}$ However, these studies have been few and pose problems of external validity (i.e., the degree to which local studies on non-randomly selected communities can be extrapolated to the general population). ${ }^{7}$ The annual rate of acute cases of Chagas' disease notified by each province might be used as an index of present human transmission of $T$. cruzi, but most primary cases are not apparent, patients may not seek medical attention because of distance to health facilities and lack of transportation or economic means, and under-reporting within the health system may be frequent. The prevalence of seropositivity for T. $\mathrm{cru}$ $z i$ among voluntary blood donors, who are not a random sample of the population, pose insurmountable problems of selection bias. In contrast, school children ${ }^{8}$ and military recruits $^{9}$ constitute accessible population groups that may be used to identify risk factors or assess the impact of control programs at various spatial scales.
According to Argentine law, all native or naturalized men born within a calendar year were summoned for military service at the age of 21 (until 1976) or 18 years (since 1977) until 1994, when the mandatory draft was discontinued. Each year, a general health survey of all recruits was carried out by the National Ministry of Public Health and Social Action. These annual surveys gave the unique opportunity to define the geographic distribution of human T. cruzi infection and assess the long-term effects of the combined triatomine and blood bank control program initiated between 1961 and 1963. This is the first study using nationwide, unselected cohorts of all men born throughout a country to assess the impact of a Chagas' disease control program over a period of approximately 30 years.

The combined control program reduced the seroprevalence of $T$. cruzi from $10.1 \%$ in some 210,000 Argentine men 21 years of age born from 1944-1947 to 5.8\% in those born in 1963 and examined for antibodies in $1981 . .^{9}$ At this time, however, some provinces still showed high prevalence rates of seropositivity for $T$. cruzi for undetermined reasons. In addition, the triatomine control program experienced several changes over time among and within provinces whose long-term impact on the transmission of $T$. cruzi has not been assessed. Therefore, a sustained effort to monitor the expected decline in prevalence rates of seropositivity for $T$. cruzi was considered necessary and feasible.

In this study we report the nationwide serologic results of nearly 1.8 million military recruits drafted from 1981 to 1993, i.e., 20-31 years after the onset of the control program in Argentina. Province-specific prevalence rates of domiciliary infestation by Triatoma infestans assessed in 1982, 1987, and 1992 were correlated with the rates of seropositivity for $T$. cruzi in young men. Data published in initial or interim reports ${ }^{9-12}$ are here refined, clarified, and corrected when necessary. 


\section{MATERIALS AND METHODS}

The Argentine Chagas' Control Program. Attempts to control Triatoma infestans were initiated in the Provinces of Chaco, La Rioja, Santiago del Estero, and Catamarca in the late 1940 s. ${ }^{13,14}$ The serologic and electrocardiographic surveys carried out by Rosembaum and Cerisola ${ }^{15,16}$ documented high seroprevalence rates of $T$. cruzi infection and associated heart disease in rural communities. These findings stimulated the organization of a national triatomine control program in 1961 and the creation of two institutions: the National Chagas Service, to carry out triatomine control actions, and the National Institute for Research and Diagnosis of Chagas' Disease "Dr. Mario Fatala Chabén" (INDIECH, formerly Sanitary Laboratory), to perform serologic diagnosis of T. cruzi infection, and control blood donors. Eleven provinces (Chaco, La Rioja, Salta, Jujuy, Santiago del Estero, Catamarca, Tucumán, San Juan, Córdoba, Santa Fe, and San Luis) started the program in $1961-1962,{ }^{17}$ and nine other provinces joined the program in the early 1970s (Formosa, La Pampa, Neuquén, Mendoza, Río Negro, Misiones, Corrientes, Entre Ríos, and Buenos Aires). The program planned to employ 1,100 spraymen to treat nearly 2.2 million houses in 3-5 years at a cost of (1964) US \$51 million. By 1968, nearly 450,000 houses had been sprayed, but the program objectives were not achieved due to budget constraints. ${ }^{18}$ Triatoma infestans bugs infected with $T$. cruzi were detected in every province within its distribution range. ${ }^{3}$ Triatomine control actions were carried out in all of the affected provinces by 1979 .

The triatomine control program was based on the application of insecticides to domestic and peridomestic premises by qualified personnel organized under a vertical, centralized structure. ${ }^{17}$ After an initial preparatory phase, in the attack phase all houses in a given community were sprayed with insecticides and re-treated after approximately two or three months. In the subsequent vigilance phase, the program included regular assessments of house infestations through timed manual capture and selective treatments of the reinfested houses. A massive spray of all house units was recommended when the rate of house reinfestation surpassed $30 \%$. These guidelines were followed also in the $1980 \mathrm{~s} .{ }^{19}$ In practice, many areas never reached the vigilance phase, and some sparsely populated departments were treated for the first time in the late 1980s (e.g., Department Moreno in Santiago del Estero). ${ }^{20}$ The chlorinated insecticide gamma-benzene hexachloride, at an intended dose of $0.5 \mathrm{~g} / \mathrm{m}^{2}$ of sprayed surface, was decreasingly used until 1983; organophosphorous insecticides (fenitrothion and mercaptothion, $2-2.5 \mathrm{~g} / \mathrm{m}^{2}$ ) were used from 1976 to 1989. Pyrethroids, mainly deltamethrin in a suspension at a concentration of 25 $\mathrm{mg} / \mathrm{m}^{2}$, have been increasingly applied since the early $1980 \mathrm{~s}$. Since 1979, the triatomine control program was decentralized and the operational responsibility was transferred to the provinces. In some provinces, control actions were inserted successfully within the primary health care system (e.g., Jujuy) while in others the experience was unsuccessful (e.g., Santiago del Estero). The main characteristic of this period was the heterogeneity, both spatial and temporal, in the execution of control actions. The annual number of houses sprayed with insecticides at each province was obtained from the available records kept at the National Chagas Service in Córdoba. The total number of units potentially at risk of infestation with Triatoma infestans was estimated as 800,000 houses in $1992 .^{10}$

The serologic control of blood donors for antibodies to $T$. cruzi was initiated in Buenos Aires and Córdoba in 1963$1964 .{ }^{21}$ This was later extended to all provinces in the $1970 \mathrm{~s}$ to achieve complete coverage of blood banks when a national law enacted in 1980 enforced such practice.

Selection of study subjects. Prospective military recruits from all over the country were randomly selected from each 18-year-old birth cohort according to their identity card number. The prospective recruits were summoned at 34 reconnaissance centers according to their permanent residence place when they were 16 years old, as stated in the identity cards. The total number of young men finally drafted depended on annual budget allocations, which followed a decreasing trend until the mandatory draft was discontinued in 1994. Thus, the number of young men that were examined for antibodies to T. cruzi decreased from 212,615 in 1981 to 80,068 in 1993 (Appendix 1), but this did not produce any selection bias because each study cohort was randomly selected. The Argentine National Ministry of Public Health and Social Action reviewed and approved the study procedures.

Serology. Blood samples were obtained by venipuncture and allowed to clot; after centrifugation and separation, the sera were mixed 1:1 in buffered glycerin for preservation at room temperature ${ }^{22}$ and then shipped to the 39 members of the national laboratory network. There the sera were screened for antibodies to $T$. cruzi by indirect hemagglutination (IHA) using a 1:8 serum dilution as the cut-off value to ensure a sensitivity of $100 \%$; the specificity was $95 \% .{ }^{9}$ In a second step, the samples reactive in the screening were retested by IHA and indirect immunofluorescence assay (IFA) for confirmation using double serum dilutions from 1:8 to 1 : 1,024 (for IHA) or 1:32 to 1:128 (for IFA). Only in 1981 were all the positive sera shipped to the national reference center (INDIECH) for confirmation. The antigens used were a mixture of 20 human and animal strains of $T$. cruzi that originated from Argentina and neighboring countries. The standardized serologic procedures used by all laboratories from 1981 to 1993 were previously described. ${ }^{9}$ Seroreactivity for $T$. cruzi was demonstrated by IHA and IFA titers $\geq$ 32. These tests have a sensitivity of $99 \%$ and a specificity of $98 \%$, giving cross-reactions with Trypanasoma rangeli (not yet detected in Argentina) and Leishmania sp. ${ }^{23}$ Samples reactive by both tests were considered seropositive. However, in case of discordant results between techniques a new blood sample was taken and the tests were repeated. In cases of new discordant results, these individuals were considered seronegative for $T$. cruzi. All seropositive individuals were excluded from military service.

Quality control procedures were indispensable for such a long-term program that included numerous and widespread laboratories. The aim of this program was to improve the performance of the participating laboratories and assess the reliability of the serologic results. Quality control procedures were based on the agreement of serum panel results sub- 
mitted for confirmation to INDIECH by all participating laboratories from 1981 to $1986 .{ }^{24}$ The quality control program included: 1) internal quality control tests, in which positive and negative control sera were monitored on a daily basis, and 2) external quality control, consisting of proficiency tests with unknown positive and negative control sera provided by the national reference center, and confirmation of serum results submitted to the national reference center by the participating laboratories. These proficiency and confirmation tests were carried out annually before the mass serologic screening; probable sources of error were identified and implementation of corrective measures were introduced when necessary. ${ }^{24}$ In cooperation with the neighboring countries, the national reference center has been coordinating an international reference serum panel for the control of Chagas' disease serology since 1993.

Entomology. Triatomine surveys were carried out in every province as part of their ongoing programs. Skilled teams from the Chagas' Control Services visited each house and searched for domiciliary Triatoma infestans before and after spraying the roof and walls with $0.2 \%$ tetramethrin, totaling $30 \mathrm{~min}$ per house (one person-hour per house). At some provinces (Salta and Jujuy), most of these searches were carried out by primary health care agents and did not use a flushing-out agent.

Statistical analysis. The relationship between seropositivity for $T$. cruzi (SEROPOS, the dependent variable) and survey year was studied by maximum likelihood logistic multiple regression analysis using the logistic-binomial model for indistinguishable data from EGRET software. ${ }^{25}$ Logistic regression analysis was preferred to standard linear regression because the data for $T$. cruzi infection are binary for an individual person, and for a sample of persons yield fractions between 0 and 1 that tend to have a binomial distribution. Seropositivity was indexed as 1 and seronegativity as 0 . Survey years were enumerated from 1 to 13 .

\section{RESULTS}

Nearly 1.8 million men 18 years of age were examined for antibodies to T. cruzi from 1981 to 1993 (Appendix 1). The sampling fraction among provinces varied little over years except for 1990-1991, when a significantly greater proportion of all recruits came from the Province and City of Buenos Aires. After a seropositivity rate of $10.1 \%$ was determined for recruits examined in 1965-1969 (as determined by IHA and complement fixation tests), a highly significant decrease occurred in the overall prevalence of seropositivity for $T$. cruzi from $5.8 \%$ in 1981 to $1.9 \%$ in 1993 (Figure 1), as determined either by a logistic regression $($ SEROPOS $=-2.717-0.0848 \times$ YEARS, standard error (SE) of intercept $=0.007, \mathrm{SE}$ of coefficient $=0.0012, \chi^{2}=$ 5533.8 , degrees of freedom $(\mathrm{df})=1, P<0.0001$ ) or a linear regression analysis (SEROPOS $=0.0595-0.00369 \times$ YEARS, SE of intercept $=0.00315$, SE of coefficient $=$ $0.00040, \mathrm{~F}=72.2, \mathrm{df}=1$ and $11, P<0.0001)$. These prevalence rates of seropositivity for $T$. cruzi were mistakenly taken as incidence rates of $T$. cruzi infection elsewhere. ${ }^{11,12}$

The time series of cross-sectional surveys shows apparent

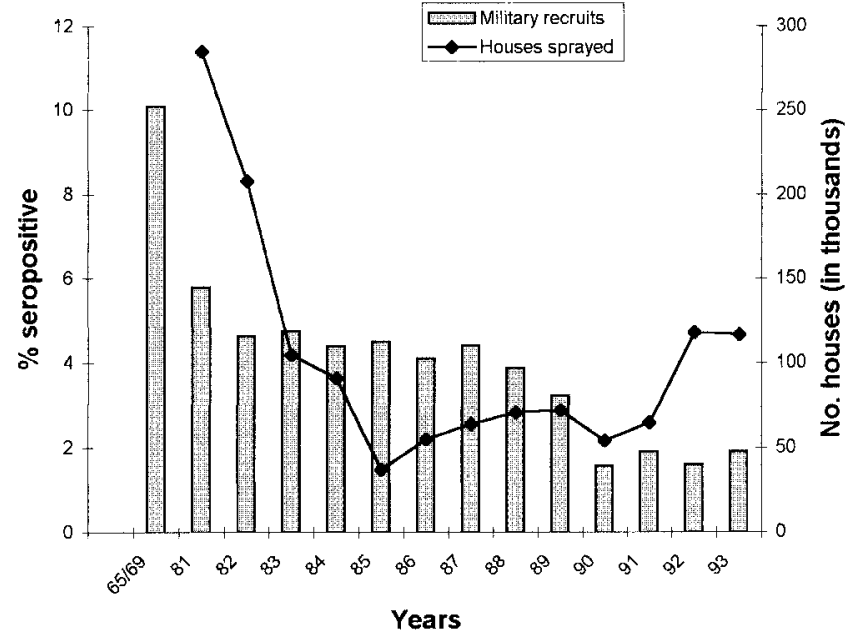

FIGURE 1. Prevalence rate of seropositivity for Trypanosoma cruzi in young men summoned for military service and annual rate of insecticidal sprays between 1965 and 1993 in Argentina.

deviations from a linearly decreasing trend (Figure 1). After a marked decrease from 1981 to 1982 , overall seropositivity rates were nearly constant around $4.5 \%$ until 1987 and then showed a steady decrease until 1990, in which they stabilized at nearly $1.8 \%$. The annual rate of insecticidal treatments decreased from 216,000-300,000 sprays in 19781981 to nearly 37,000 sprays in 1985 , and then increased to nearly 120,000 sprays in 1993 , although with a decrease in 1990-1991 as a consequence of the 1989 economic crisis. The annual rate of spraying surpasses the actual number of different houses sprayed because according to the control program guidelines, houses would have to be sprayed twice in the same year when BHC was used.

The overall temporal decrease of seroprevalence for $T$. cruzi by geographic region and province between 1981 and 1993 was heterogeneous (Figure 2), as determined by logistic regression analysis (Table 1). For comparison, Figure 2 also shows the prevalence of seropositivity in 1965-1969 as isolated points on the left of each graph. In Patagonia, with very low or null domiciliary infestations, seropositivity rates decreased from the $2.2-6.0 \%$ range in 1981 to less than $1.6 \%$ in 1993 (Figure 2A). This reduction was due mostly to highly significant decreases in Río Negro, Neuquén, and Chubut $(P<0.001)$, while Santa Cruz $(P=0.52)$ and Tierra del Fuego $(P=0.08)$ showed no statistically significant differences over this period of time. The seropositivity rates of recruits from the City and the Province of Buenos Aires, where established domiciliary infestations had not been detected, decreased in a highly significant way from $2.3-2.5 \%$ in 1981 to $0.7 \%$ in 1993 (Figure 2B). Seropositivity rates from the neighboring provinces of Córdoba and Santa Fé showed a highly significant decreasing trend throughout, although with a clearly anomalous estimate for Santa Fé in 1986. In the northeastern provinces (Misiones, Corrientes, and Entre Ríos), which usually had lower domiciliary infestation rates than other northern provinces, the period seropositivity rates showed a statistically highly significant decreasing trend, though with irregular fluctuations in Entre Ríos and Corrientes (Figure 2C). All northwestern provinces 

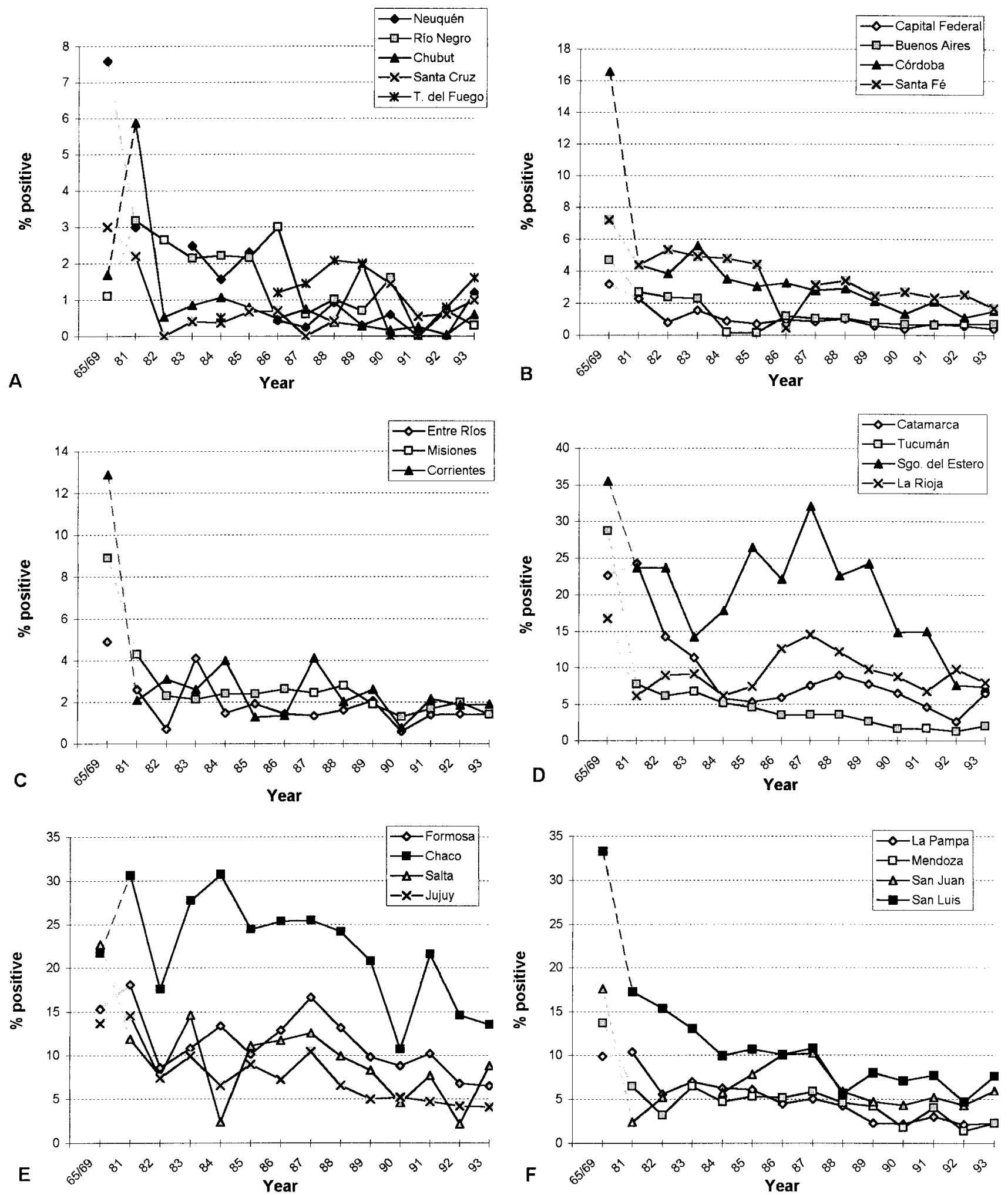

FIGURE 2. Province-specific prevalence rate of seropositivity for Trypanosoma cruzi in young men summoned for military service according to geographic area between 1981 and 1993 in Argentina. 
TABLE 1

Logistic regression analysis of seropositivity rates for Trypanosoma cruzi in military recruits according to source province, Argentina, 19811993

\begin{tabular}{|c|c|c|c|c|c|c|}
\hline Province & Intercept & $\begin{array}{c}\text { SE of } \\
\text { intercept }\end{array}$ & Coefficient & $\begin{array}{c}\text { SE of } \\
\text { coefficient }\end{array}$ & $\chi^{2}$ & $P$ \\
\hline \multicolumn{7}{|c|}{ Triatomine control program started in $1961-1962$} \\
\hline Santa Fé & -2.7900 & 0.0240 & -0.0873 & 0.0044 & 417.5 & $<0.001$ \\
\hline Chaco & -0.9005 & 0.0184 & -0.0439 & 0.0034 & 166.6 & $<0.001$ \\
\hline Córdoba & -2.8690 & 0.0260 & -0.0989 & 0.0049 & 441.3 & $<0.001$ \\
\hline Catamarca & -1.4664 & 0.0436 & -0.1512 & 0.0085 & 371.4 & $<0.001$ \\
\hline Salta & -2.1133 & 0.0303 & -0.0309 & 0.0053 & 35.2 & $<0.001$ \\
\hline Jujuy & -1.9492 & 0.0371 & -0.0953 & 0.0070 & 202.6 & $<0.001$ \\
\hline Tucumán & -2.3365 & 0.0325 & -0.1393 & 0.0071 & 424.1 & $<0.001$ \\
\hline Santiago del Estero & -1.2156 & 0.0209 & -0.0155 & 0.0037 & 18.0 & $<0.001$ \\
\hline La Rioja & -2.4649 & 0.0549 & 0.0238 & 0.0078 & 9.3 & 0.002 \\
\hline San Juan & -3.2582 & 0.0478 & 0.0630 & 0.0071 & 76.4 & $<0.001$ \\
\hline San Luis & -1.5744 & 0.0440 & -0.1001 & 0.0075 & 193.1 & $<0.001$ \\
\hline \multicolumn{7}{|c|}{ Triatomine control program started in the $1970 \mathrm{~s}$} \\
\hline Buenos Aires & -3.6760 & 0.0190 & -0.1473 & 0.0037 & 1796.7 & $<0.001$ \\
\hline Entre Ríos & -3.7212 & 0.0536 & -0.0445 & 0.0081 & 31.3 & $<0.001$ \\
\hline Misiones & -3.3870 & 0.0519 & -0.0558 & 0.0092 & 38.3 & $<0.001$ \\
\hline Corrientes & -3.5476 & 0.0510 & -0.0232 & 0.0082 & 8.1 & 0.005 \\
\hline Formosa & -1.8950 & 0.0394 & -0.0269 & 0.0066 & 16.8 & $<0.001$ \\
\hline La Pampa & -2.2077 & 0.0606 & -0.1293 & 0.0111 & 156.6 & $<0.001$ \\
\hline Mendoza & -2.6947 & 0.0294 & -0.0589 & 0.0049 & 151.8 & $<0.001$ \\
\hline Neuquén & -3.3208 & 0.1088 & -0.1923 & 0.0190 & 120.6 & $<0.001$ \\
\hline Río Negro & -3.1453 & 0.0819 & -0.1785 & 0.0150 & 166.6 & $<0.001$ \\
\hline \multicolumn{7}{|c|}{ Without triatomine control program } \\
\hline Chubut & -3.1805 & 0.1077 & -0.2959 & 0.0262 & 195.5 & $<0.001$ \\
\hline Santa Cruz & -5.0571 & 0.2974 & -0.0231 & 0.0364 & 0.4 & 0.520 \\
\hline Tierra del Fuego & -5.6907 & 0.6893 & 0.1170 & 0.0698 & 3.0 & 0.085 \\
\hline Ciudad de Buenos Aires & -3.9695 & 0.0468 & -0.1221 & 0.0090 & 206.5 & $<0.001$ \\
\hline
\end{tabular}

TABLE 2

Prevalence rates of seropositivity for Trypanosoma cruzi infection in 18-year-old men from Argentina drafted into military service in 1965-1969, 1981, and 1993

\begin{tabular}{|c|c|c|c|c|}
\hline \multirow[b]{2}{*}{ Provinces } & \multicolumn{3}{|c|}{ Percentage of seropositive men } & \multirow[b]{2}{*}{$P \dagger$} \\
\hline & $1965-1969 *$ & $1981 *$ & 1993 & \\
\hline Buenos Aires & 3.2 & 2.5 & 0.4 & $<0.001$ \\
\hline City of Buenos Aires & 4.7 & 2.3 & 0.7 & $<0.001$ \\
\hline Catamarca & 22.7 & 24.3 & 6.5 & $<0.001$ \\
\hline Córdoba & 16.6 & 4.4 & 1.5 & 0.001 \\
\hline Corrientes & 12.9 & 2.1 & 1.9 & NS \\
\hline Chaco & 21.7 & 30.6 & 13.5 & $<0.001$ \\
\hline Chubut & 1.8 & 6.0 & 0.6 & $<0.001$ \\
\hline Entre Ríos & 4.9 & 2.6 & 1.4 & $<0.001$ \\
\hline Formosa & 15.3 & 18.1 & 6.5 & $<0.001$ \\
\hline Jujuy & 13.7 & 14.6 & 4.1 & $<0.001$ \\
\hline La Pampa & 9.9 & 10.4 & 2.3 & $<0.001$ \\
\hline La Rioja & 16.8 & 6.2 & 8.0 & NS \\
\hline Mendoza & 13.7 & 6.5 & 2.3 & $<0.001$ \\
\hline Misiones & 8.9 & 4.3 & 1.4 & $<0.001$ \\
\hline Neuquén & 7.6 & 3.0 & 1.2 & $<0.001$ \\
\hline Río Negro & 1.1 & 3.3 & 0.3 & $<0.001$ \\
\hline Salta & 22.7 & 11.9 & 8.8 & 0.01 \\
\hline San Juan & 17.6 & 2.4 & 5.9 & $<0.001$ \\
\hline San Luis & 33.3 & 17.3 & 7.6 & $<0.001$ \\
\hline Santa Cruz & 3.0 & 2.2 & 1.0 & NS \\
\hline Santa Fé & 7.2 & 4.4 & 1.7 & $<0.001$ \\
\hline Santiago del Estero & 35.5 & 23.7 & 7.3 & $<0.001$ \\
\hline Tucumán & 28.7 & 7.8 & 2.0 & $<0.001$ \\
\hline Tierra del Fuego & ND & ND & 1.6 & ND \\
\hline Total & 10.1 & 5.8 & 1.9 & $<0.001$ \\
\hline
\end{tabular}

$\dagger \chi^{2}$ test with one degree of freedom comparing 1981 and 1993. NS $=$ not significant

$*$ Data taken from published sources $3,9,18,21$ showed statistically significant decreases in seropositivity rates except La Rioja, where a significant increasing trend $(P=0.002)$ occurred (Figure $2 \mathrm{D})$. In the neighboring provinces of Santiago del Estero and Catamarca, the seropositivity rates started from nearly $24 \%$ in 1981 to reach $6 \%$ in 1993 but with quite contrasting trajectories (Figure 2D). Other northern provinces (Salta, Jujuy, Formosa, and Chaco) experienced a highly significant decreasing trend in seropositivity rates (Figure 2E). In western and central provinces, seropositivity rates for military recruits from San Luis, La Pampa, and Mendoza exhibited highly significant decreasing trends while those from San Juan showed a highly significant increase with a peak in 1987 (Figure 2F).

The logistic regression coefficients for each province give an indication of the impact of the control program on the seropositivity rates of each province's recruits (Table 1). Two of the 11 provinces that started the program in 1961-1962 showed a significant increase in seropositivity rates, whereas the nine provinces that started actions in the early 1970s experienced significant decreases. In spite of the difference of 10 years between the onset of actions in both groups, regression coefficients were not significantly different between groups ( $t$ test for independent samples $=1.12, \mathrm{df}=$ $18, P=0.28)$.

Table 2 shows the province-specific distribution of prevalence rates of seropositivity for $T$. cruzi in military recruits examined in 1965-1969 (born in 1944-1948 prior to the existence of any control action), 1981, and 1993. Comparison between 1981 and 1993 seropositivity rates yielded either highly significant $(P<0.001)$ or significant $(P<0.01)$ reductions in all provinces except Corrientes, La Rioja, and 

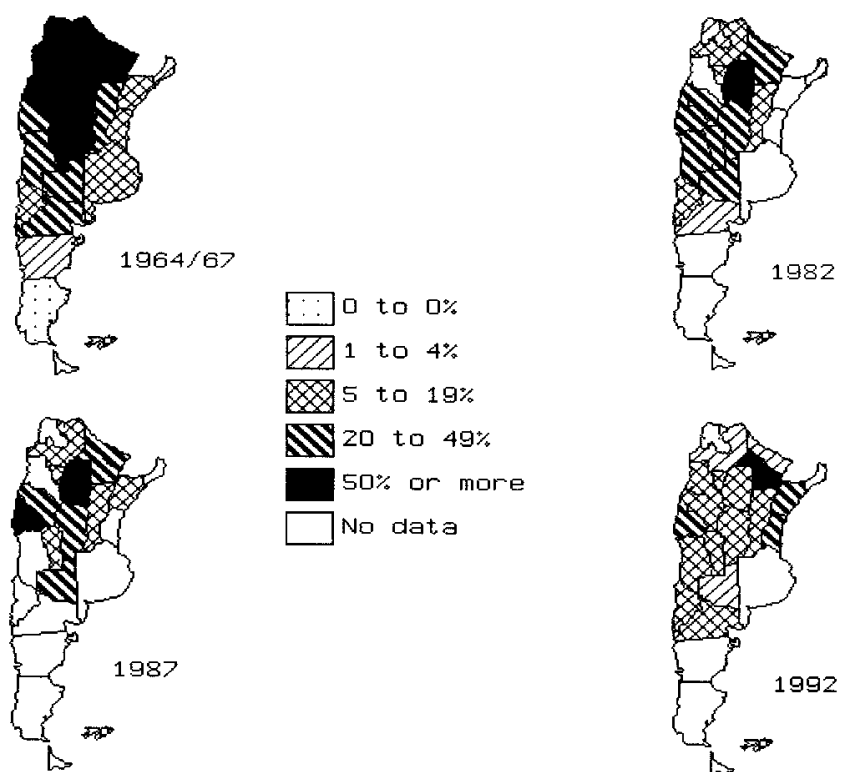

$50 \%$ or more No data

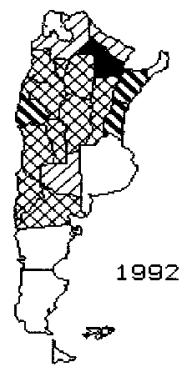

FIGURE 3. Province-specific domiciliary infestations by Triatoma infestans between 1964 and 1992 in Argentina. Data sources: 1964-1967, ${ }^{3}$ and Servicio Nacional de Chagas, Córdoba, Argentina (Segura EL, unpublished data).

Santa Cruz $(P>0.05)$, and a statistically highly significant increase in San Juan from $2.4 \%$ to $5.9 \%(P<0.001)$. In recruits examined in 1981 who had been born in 1963, high seropositivity rates surpassing $10 \%$ were observed in eight provinces. Of recruits examined for antibodies in 1993 who had been born in 1975, only those from Chaco still showed seropositivity rates greater than $10 \%$, while recruits from seven provinces had seropositivity rates that ranged from $5 \%$ to $10 \%$.

Three years after the start of the control campaign, in 1964-1967, 15 (68\%) of 22 provinces within the distribution range of Triatoma infestans had high ( $>20 \%)$ prevalence rates of domiciliary infestation (Figure 3). The number of provinces with a high rate of domiciliary infestation decreased to $9(41 \%)$ provinces in 1982, 7 (32\%) provinces in 1987 , and $4(18 \%)$ provinces in 1992. The total number of houses inspected for evidence of domiciliary infestation was 2,716 between 1964 and $1967^{3}$ (Carcavallo RU, unpublished data), 185,233 houses in $1982,52,347$ houses in 1987 , and 391,389 houses in 1992. The province-specific prevalence of infestation by Triatoma infestans in 1982 correlated positively and significantly with seropositivity rates in every survey year (range of correlation coefficients, $r=0.50-0.77, \mathrm{n}$ $=16, P<0.05$ ), except in 1981 and 1983, which were marginally significant $(0.05<P<0.1)$. Infestation in 1987 was significantly and positively correlated with seropositivity rates only in 3 of the 13 cross-sectional surveys, whereas infestation in 1992 showed no significant correlation with any survey.

\section{DISCUSSION}

This study unequivocally demonstrates a marked decrease in the overall prevalence rates of seropositivity for $T$. cruzi in young men from Argentina, and shows that the decrease has been heterogeneous among and within regions over time. Most of the decrease in the seropositivity rates of 18-year old men may be attributed to insecticidal sprays against Triatoma infestans because: 1) There was a statistically significant positive correlation between the province-specific prevalence rates of domiciliary infestation by Triatoma infestans in 1982 and seropositivity for $T$. cruzi in military recruits, which gives support to a causal relationship between both variables. 2) Screening of potential blood donors for antibodies to T. cruzi was initiated in 1963-1964 (when the 1981 cohort was born) and achieved almost complete coverage of blood banks in the early 1980s. Furthermore, individuals $<$ 18 years of age usually constitute a very small fraction of the patients receiving blood transfusions. These facts suggest that all the study individuals were exposed to a reduced and decreasing likelihood of acquiring $T$. cruzi infection via infected blood. 3) Control of congenital transmission of $T$. cruzi at some large hospitals and maternities was started in 1992; therefore, this program could not have affected the risk of vertical infection of the cohorts born prior to this specific program. 4) Transmission of $T$. cruzi infection through organ transplants is of marginal occurrence.

Demographic changes over decades may confound or modify the long-term effects of a nationwide control program. Although housing, working, and living conditions in some of the affected rural areas experienced visible improvements over the three decades (1960-1990) relevant to this study, such changes have been relatively slow and heterogeneous among and within provinces. For example, the nationwide number of houses with roofs or walls that may favor triatomine infestation (adobe, mud-stick, wood, thatch) increased 1.7 times from 1960 to 1991 (from 440,000 to 813,000 houses), while the human population increased proportionally by a factor of 1.85 (from 20 to 34 million) in the same period.26,27 Among the most affected northern and western provinces, with high fertility rates and high rates of pre-adult or adult migration to other provinces, the size of the human populations was fairly stable in 1960-1970, and increased thereafter. ${ }^{28}$ The observed tendency of rural inhabitants to migrate to urban centers over time ${ }^{28,29}$ probably exerted a greater impact on the age structure of the rural populations left behind than on their size because most of the migrants were 15 years of age or older. Rural communities in northern Argentina were, and still are, composed of many school age children and few working age adults, many of whom migrate seasonally or transiently to other areas for temporal jobs. It is fairly common that rural families in need receive some regular economic support from their first-degree relatives employed elsewhere. Therefore, the long-term decrease in seropositivity rates for $T$. cruzi cannot be attributed to significant and mass improvements in housing conditions or to rapidly decreasing populations in the affected rural areas.

Demographic factors may also help explain some of the patterns observed. Internal migrations from the impoverished northern provinces to Buenos Aires (City and Province) and Patagonia in search of permanent jobs and more resourceful environments undoubtedly explain the persistent detection of seropositive men in areas without domiciliary infestation. These migratory flows were important since 
1947 to the 1970s (particularly those headed for Patagonia in the 1960s and 1970s), but only comprised 8\% (in 19651970) or 6\% (in 1975-1980) of the total Argentine population at those times, and only one-third of the migrants originated from rural areas. ${ }^{28}$ Most of the inter-provincial migrants were men between 15 and 44 years of age, an age class that shows high rates of seropositivity for $T$. cruzi at the source provinces. The available evidence is still insufficient to assess whether people infected with $T$. cruzi have an increased odds of emigrating to other provinces. The overall temporal decrease in seropositivity rates in Buenos Aires and the southernmost Patagonian provinces may therefore reflect the decreasing likelihood of $T$. cruzi infection at the source provinces that fed the migratory flow.

The study subjects comprised unselected cohorts regarding place of residence, exposure to triatomines, and health or socioeconomic status, and thus constituted a representative fraction of each provincial population. Individuals judged to be in an unhealthy state at the general survey were excluded after examination, not before blood samples were taken. Military recruits were summoned according to their permanent residence place at the age in which they obtained their identity cards (16 years old), regardless of their address at the time of the draft. At a province-wide spatial scale and with such large sample sizes, small discrepancies between places of birth or permanent residence and reconnaissance center may be negligible for detecting time trends. The reduction in the total number of recruits since 1985 did not produce any selection bias because those finally summoned were randomly selected from each cohort according to their identity card number. The province-specific sampling fraction of each cohort was almost constant over the study years, with the exception of 1990 and 1991, in which a proportionally greater number of recruits from the City and Province of Buenos Aires was examined as a consequence of the 1989 economic crisis and subsequent budget constraints. Since many community-wide studies failed to obtain significant evidence of a gender-specific greater risk of infection with $T$. cruzi in bivariate ${ }^{30,31}$ or multivariate analyses, ${ }^{32}$ we believe that the present results for young men may be generalized to each complete birth cohort.

Our study gave detailed attention to the design of a quality assurance program to warrant the reliability of the serodiagnoses carried out at 39 laboratories over more than a decade. In spite of such controls and the observed good performance of the laboratory network, the time series of seropositivity rates presented some outlying, suspect values (Salta in 1984, Santa Fé in 1986) that remain unexplained. Regarding the entomologic information, domiciliary infestation estimates of Triatoma infestans did not arise from a random sample of localities or houses, but as part of regular program operations focusing on affected rural areas within operational feasibility by each provincial program. In addition, some provinces (Salta and Jujuy) did not use the standard method of timed manual capture, which makes the assessments not directly comparable among provinces over the years. Therefore, the entomologic indices should be taken as gross, possibly biased indices of domiciliary infestation.

Age-prevalence curves obtained at 13 rural areas from seven Argentine provinces ${ }^{6}$ or Brazil ${ }^{30}$ suggest that most cas- es of T. cruzi infection are produced before the age of 20 years, possibly at a constant or slightly decelerating rate. For example, seropositivity rates for $T$. cruzi in 18 year old men reached nearly $70 \%$ in the most affected rural departments of the Chaco province in $1981 .{ }^{33}$ Longitudinal studies have documented a shift to the right of the age-specific seroprevalence curves both for humans ${ }^{5}$ and $\operatorname{dogs}^{34}$ infected with $T$. cruzi after effective control measures against triatomines were undertaken. In theory, therefore, the effects of such actions on cohort-seropositivity rates should become apparent without the need of a latent or waiting time.

Results of each annual serologic evaluation of military recruits was immediately available to chief officers of the provincial control programs and health authorities, and might have been helpful to monitor the expected effects of past actions and target more precisely current control actions. However, in the context of a disorganized decentralization of the national control program, the dominant scenario since the late 1970 s was lack of political decision and sufficient funding to sustain insecticiding operations and set up the planned vigilance phase. In the absence of further control actions after the attack phase with the modern pyrethroids, domiciliary reinfestation by Triatoma infestans most probably increased exponentially and renewed human transmission of $T$. cruzi occurred 3-4 years after intervention. ${ }^{20}$ Reinfestation surely proceeded even more rapidly with organo-chlorine insecticides in the past. Therefore, the results of the present study mostly reflect the impact of a control campaign in which little or no sustained surveillance against domiciliary reinfestation was carried out. The more distant the community, the less likely that the control teams would repeat insecticidal sprays in due time, likely leaving behind less protected areas in which human transmission of $T$. cruzi resurged in a few years. Notwithstanding these shortcomings, control actions exerted a highly significant impact on seropositivity rates, probably because vector-mediated transmission of $T$. cruzi to humans is relatively inefficient and requires high density infestations. ${ }^{35}$ The irregularity of control actions likely resulted in the irregular fluctuations in seropositivity rates at some provinces. Such lack of sustainability, especially in large provinces with dispersed rural populations, set a limit to the decrease of seropositivity rates and prompted a revised control strategy in which the attack and vigilance actions were carried out with community participation. ${ }^{36,37}$

Acknowledgments: We thank Gladys Wynne de Martini, Liliana Abramo Orrego, Mirta Carlomagno, and the staff at the Instituto Nacional de Parasitología Dr. Mario Fatala Chabén and Servicio Nacional de Chagas (Argentina) for providing active support throughout this study. The following people have been instrumental in the serologic screening: L. A. Arango, N. Boschetto, A. Linares, J. Pratolongo, A. R. de Marteleur, M. E. Veron, J. A. Pugliesse, G. M. Bo, H. A. Castro, I. Galuffa, M. Streiger, E. Acebal, M. A. L. de Basualdo, M. B. R. de Muller Dos Reis, E. Hure, H. C. Saure, M. A. Arca, E. J. Deschutter, G. J. Botello, M. Lizarazu, M. C. Salomón de Paulos, M. Q. de Franza, R. A. de Rodríguez, L. Bugurrarena, V. Moreno, N. A. González, D. Scozzini, C. Ziaurriz, M. C. Mallimacci, M. C. Vera, A. F. de Salcedo, S. M. C. de Avalos, M. M. L. de Fernandez, I. T. de Ovejero, A. M. S. de Ganassin, G. P. Barbieri, H. G. de Riboldi, and R. A. Dacal. Valuable historical information regarding triatomine control actions was provided by $\mathrm{J}$. M. Gualtieri. Alejandro Katzin provided helpful comments. 
Financial support: This study was supported by the National Ministry of Health and Social Action of Argentina.

Authors' addresses: Elsa L. Segura, Estela N. Cura, Juan C. Lansetti, and Ada R. Campanini, ANLIS Dr. Carlos G. Malbrán, Av. Velez Sarsfield 563, C1282AFF Buenos Aires, Argentina. Sergio A. Sosa Estani, CENDIE, Paseo Colón 568, C1063ACS Buenos Aires, Argentina. Jorge Andrade, Secretaría de Movilización, Av. 9 de Julio 1016, 1032 Buenos Aires, Argentina. Ana M. de Rissio and Manuel Alvarez, Instituto Nacional de Chagas Dr. Mario Fatala ChabénANLIS Dr. Carlos G. Malbrán, Paseo Colón 568, C1063ACS Buenos Aires, Argentina. Sonia B. Blanco, Servicio Nacional de Chagas, Ministerio de Salud y Acción Social de la Nación, 9 de Julio 356, 5000 Córdoba, Argentina. Ricardo E. Gürtler, Laboratorio de Ecología General, Departamento de Ciencias Biológicas, Universidad de Buenos Aires, C1428EHA Buenos Aires, Argentina, and ANLIS Dr. Carlos G. Malbrán, Av. Velez Sarsfield 563, C1282AFF Buenos Aires, Argentina.

Reprint requests: Elsa L. Segura, CENDIE, Paseo Colón 568, C1063ACS, Buenos Aires, Argentina.

\section{REFERENCES}

1. Moncayo A, 1992. Chagas' disease: epidemiology and prospects for interruption of transmission in the Americas. World Health Stat $Q$ 45: 276-279.

2. Esquivel ML, Segura EL, 1994. Estimación del número de infectados chagásicos en Argentina. Medicina (B Aires) 54 (suppl 1): 91-92.

3. Carcavallo RU, Martínez A, 1968. Entomoepidemiología de la República Argentina. Investigaciones Cientificas de la Fuerzas Armadas Argentinas 13: 1-143.

4. Schmunis GA, Zicker F, Moncayo A, 1996. Interruption of Chagas' disease transmission through vector elimination. Lancet 348: 1171.

5. Hoff R, Todd CW, Maguire JH, Piesman J, Mott KE, Mota EE, Sleigh A, Sherlock IA, Weller TH, 1985. Serologic surveillance of Chagas' Disease. Ann Soc Belg Med Trop 65 (suppl 1): $187-196$.

6. Chuit R, Subias E, Perez AC, Paulone I, Wisnivesky-Colli C, Segura EL, 1989. Usefulness of serology for the evaluation of Trypanosoma cruzi transmission in endemic areas of Chagas' Disease. Rev Soc Bras Med Trop 22 (suppl): 119-124.

7. Kleimbaum DG, Kupper LL, Morgerstern H, 1982. Epidemiologic Research. Principles and Quantitative Methods. New York: Van Nostrand Reinhold.

8. Andrade ALSS, Zicker F, Silva IG, Souza JMP, Martelli CMT, 1995. Risk factors for Trypanosoma cruzi infection among children in central Brazil: a case-control study in vector control settings. Am J Trop Med Hyg 52: 183-187.

9. Segura EL, Perez A, Yanovsky JF, Andrade J, Wynne de Martini GJ, 1985. Decrease in the prevalence of infection by Trypanosoma cruzi (Chagas' disease) in young men of Argentina. Bull Pan Am Health Organ 19: 252-264.

10. Anonymous, 1994. El control de la transmisión de Trypanosoma cruzi en la República Argentina. Bol Epidemiol Nac (B Aires) 2: $3-16$.

11. Anonymous, 1996. Chagas' disease. Progress toward elimination of transmission. Weekly Epidemiol Rec 71: 12-15.

12. Anonymous, 1996. Progress toward elimination of Chagas' disease transmission in Argentina. Bull Pan Am Health Organ 30: $84-86$

13. Romaña C, Alvarado CA, Tula A, Abalos JW, 1950. Campaña de gamatización antivinchuca. Primera Reunión Panamericana sobre Enfermedad de Chagas. Tucumán, Tucumán, Argentina. 1949, 57-62.

14. Soler C, 1958. Campaña piloto de erradicación de la vinchuca. Villa Mazán, 1958. Subsecretaría de Salud Pública. La Rioja, La Rioja, Argentina.

15. Rosembaum MB, Cerisola JA, 1957. Encuesta sobre la enfermedad de Chagas en el norte de Córdoba y sur de Santiago del Estero. Prensa Med Arg 44: 2713-2717.

16. Rosembaum MB, Cerisola JA, 1961. Epidemiología de la en- fermedad de Chagas en la República Argentina. O Hosp (Rio de Janeiro) 60: 75-124.

17. Anonymous, 1964. Programa Nacional de Lucha contra la Enfermedad de Chagas. Conferencia de Ministros de Salud Pública de los Países de la Cuenca del Plata. Puerto Iguazú, Misiones, 21-23 de Agosto de 1961. Dirección de Enfermedades Transmisibles, Ministerio de Salud de la Nación. City of Buenos Aires, Argentina.

18. Cichero JA, Carcavallo RU, Martínez A, 1968. Síntesis sobre epidemiología de la Enfermedad de Chagas en la República Argentina. Organización del Grupo de Estudio: Secretaría de Estado de Salud Pública y Organización Panamericana de la Salud, Córdoba, Córdoba, Argentina.

19. Gualtieri JM, 1983. Normas técnicas y de procedimientos para la lucha química contra el vector. Servicio Nacional de Chagas. Normas Coordinadas. Chagas (Cordoba) 1: 29-34.

20. Gürtler RE, Petersen RM, Schweigmann NJ, Cécere MC, Chuit R, Gualtieri JM, Wisnivesky-Colli C, 1994. Chagas' disease in northwest Argentina: risk of domestic reinfestation by Triatoma infestans after a single community-wide application of deltamethrin. Trans $R$ Soc Trop Med Hyg 87: 12-15.

21. Cerisola JA, Rabinovich A, Alvarez M, Di Corleto CA, Pruneda J, 1972. Enfermedad de Chagas y la transfusión de sangre. Bol Oficina Sanit Panam 73: 203-221.

22. Pérez AC, Cura E, Lansetti J, Segura EL, 1990. Long-term preservation of blood samples for diagnosis of Trypanosoma cruzi infection. Trop Med Parasitol 41: 75-76.

23. Camargo ME, 1992. An appraisal of Chagas disease serodiagnosis. Wendel S, Brenner Z, Camargo ME, Rassi A, eds. Chagas Disease (American trypanosomiasis): Its Impact on Transfusion and Clinical Medicine. Sao Paulo: ISBT Brazil '92-SBHH, 165-178.

24. Cura EN, Segura EL, 1998. Quality assurance of the serologic diagnosis of Chagas' disease. Pan Am J Public Health 3: 242-247.

25. EGRET, 1993. Epidemiological Graphics, Estimation and Testing Package. Seattle, WA: Statistics and Epidemiology Research Corporation.

26. Instituto Nacional de Estadísticas y Censos, 1960. Censo de Población y Vivienda. Buenos Aires: Ministerio de Economía de la Nación.

27. Instituto Nacional de Estadísticas y Censos, 1991. Censo de Población y Vivienda. Buenos Aires: Ministerio de Economía de la Nación.

28. Instituto Nacional de Estadísticas y Censos, 1980. Censo de Población y Vivienda. Buenos Aires: Ministerio de Economía de la Nación.

29. Pinto Dias JC, 1987. Epidemiology of Chagas disease in Brazil. Brener RR, Stoka AM, eds. Chagas' Disease Vectors. Volume 1. Boca Raton, FL: CRC Press.

30. Mott KE, Lehman Jr JS, Hoff R, Morrow RH, Muniz TM, Sherlock IA, Draper CC, Pugliese C, Guimaraes AC, 1976. The epidemiology and household distribution of seroreactivity to Trypanosoma cruzi in a rural community in northeast Brazil. Am J Trop Med Hyg 25: 552-562.

31. Paulone I, Chuit R, Pérez AC, Canale C, Segura EL, 1991. The status of transmission of Trypanosoma cruzi in an endemic area of Argentina prior to control attempts, 1985. Ann Trop Med Parasitol 85: 489-497.

32. Gürtler RE, Chuit R, Cecere MC, Castañera MB, Cohen JE, Segura EL, 1998. Household prevalence of seropositivity for Trypanosoma cruzi in three rural villages in northwest Argentina: environmental, demographic, and entomologic associations. Am J Trop Med Hyg 59: 741-749.

33. Gualtieri JM, Baldi EM, 1981. Análisis de una experiencia piloto de control de la enfermedad de Chagas. Prensa Méd Arg 68: 209-216.

34. Gürtler RE, Kravetz FO, Petersen RM, Lauricella MA, Wisnivesky-Colli C, 1990. The prevalence of Trypanosoma cruzi and the demography of dog populations after insecticidal spraying of houses: a predictive model. Ann Trop Med Parasitol 84: 313-323.

35. Rabinovich JE, Wisnivesky-Colli C, Solarz ND, Gürtler RE, 
1990. Probability of transmission of Chagas disease by Triatoma infestans (Hemiptera: Reduviidae) in an endemic area of Santiago del Estero, Argentina. Bull World Health Organ 68: 737-746.

36. Chuit R, Paulone I, Wisnivesky-Colli C, Bo R, Pérez A, Sosa Estani S, Segura EL, 1992. Results of a first step toward community-based surveillance of transmission of Chagas' disease with appropriate technology in rural areas. Am J Trop Med Hyg 46: 444-450.
37. Segura EL, Esquivel ML, Salomón OD, Sosa Estani S, Gómez AO, Ibarra F, Chuit R, 1994. Alternativas de control de la transmisión de Trypanosoma cruzi. In: Enfermedad de Chagas. Storino R, Milei J, eds. Buenos Aires: Mosby Doyma, 641-648. 
APPENDIX 1

Annual number of military recruits examined for antibodies to Trypanosoma cruzi in Argentina, 1981-1993*

\begin{tabular}{|c|c|c|c|c|c|c|c|c|c|c|c|c|c|}
\hline \multirow[b]{2}{*}{ Provinces } & \multicolumn{13}{|c|}{ Survey year } \\
\hline & 1981 & 1982 & 1983 & 1984 & 1985 & 1986 & 1987 & 1988 & 1989 & 1990 & 1991 & 1992 & 1993 \\
\hline Ciudad de Buenos Aires & 16,239 & 15,406 & 15,792 & 15,594 & 17,775 & 8,238 & 8,521 & 7,985 & 12,323 & 4,326 & 6,132 & 3,978 & 5,530 \\
\hline Provincia de Buenos Aires & 79,425 & 79,931 & 75,182 & 78,714 & 82,447 & 41,512 & 43,640 & 42,173 & 58,631 & 22,952 & 28,734 & 26,265 & 32,266 \\
\hline Entre Ríos & 8,196 & 4,700 & 4,535 & 8,341 & 8,481 & 3,984 & 3,920 & 4,039 & 5,569 & 692 & 3,155 & 3,682 & 5,514 \\
\hline Misiones & 5,726 & 6,384 & 6,149 & 6,704 & 6,618 & 3,363 & 3,290 & 3,248 & 4,110 & 224 & 1,704 & 1,685 & 1,779 \\
\hline Corrientes & 6,648 & 4,913 & 6,968 & 7,028 & 7,237 & 3,382 & 3,790 & 3,697 & 4,263 & 533 & 2,031 & 2,469 & 2,219 \\
\hline Santa Fé & 18,698 & 18,914 & 18,986 & 19,012 & 19,145 & 8,282 & 8,362 & 8,650 & 13,032 & 2,977 & 4,992 & 4,900 & 4,726 \\
\hline Formosa & 1,538 & 3,250 & 3,242 & 3,648 & 3,768 & 1,514 & 1,553 & 1,809 & 2,480 & 285 & 510 & 575 & 790 \\
\hline Chaco & 7,141 & 7,541 & 7,114 & 8,086 & 8,213 & 3,013 & 3,044 & 3,149 & 4,394 & 457 & 421 & 874 & 1,330 \\
\hline Córdoba & 16,906 & 19,092 & 18,188 & 18,680 & 19,930 & 8,792 & 9,066 & 9,357 & 12,086 & 2,331 & 4,454 & 4,416 & 4,874 \\
\hline Catamarca & 2,158 & 2,049 & 2,098 & 2,067 & 2,222 & 906 & 1,084 & 1,156 & 1,493 & 325 & 563 & 691 & 1,084 \\
\hline Salta & 4,104 & 6,317 & 6,508 & 6,494 & 7,128 & 3,214 & 2,783 & 2,876 & 4,555 & 887 & 1,044 & 1,118 & 1,075 \\
\hline Jujuy & 3,778 & 3,710 & 3,819 & 3,934 & 4,038 & 1,656 & 1,652 & 1,849 & 2,772 & 518 & 835 & 930 & 1,082 \\
\hline Tucumán & 8,796 & 8,759 & 8,678 & 8,417 & 9,412 & 4,013 & 4,547 & 4,623 & 5,686 & 616 & 632 & 1,040 & 636 \\
\hline Santiago del Estero & 5,963 & 6,305 & 6,382 & 6,173 & 6,616 & 3,138 & 3,034 & 3,192 & 4,158 & 431 & 709 & 723 & 1,298 \\
\hline La Rioja & 1,625 & 1,716 & 1,706 & 1,656 & 1,690 & 794 & 850 & 867 & 1,274 & 429 & 278 & 633 & 1,094 \\
\hline La Pampa & 1,745 & 1,782 & 1,827 & 1,740 & 1,803 & 966 & 946 & 826 & 1,242 & 181 & 510 & 1,026 & 1,292 \\
\hline Mendoza & 9,921 & 9,617 & 9,205 & 8,419 & 9,607 & 4,376 & 5,179 & 5,507 & 7,151 & 1,456 & 3,597 & 3,701 & 4,023 \\
\hline San Juan & 4,635 & 4,285 & 4,115 & 4,036 & 3,948 & 1,930 & 2,145 & 2,375 & 2,827 & 725 & 689 & 980 & 1,054 \\
\hline San Luis & 1,873 & 1,904 & 1,888 & 1,808 & 2,066 & 855 & 1,008 & 1,099 & 1,558 & 778 & 731 & 696 & 935 \\
\hline Neuquén & 2,005 & 510 & 2,049 & 2,370 & 2,375 & 1,142 & 1,249 & 1,296 & 2,184 & 333 & 2,051 & 2,630 & 2,161 \\
\hline Río Negro & 3,074 & 1,060 & 3,230 & 2,348 & 3,224 & 1,405 & 2,021 & 1,972 & 2,435 & 638 & 1,779 & 2,213 & 2,415 \\
\hline Chubut & 2,065 & 2,475 & 2,459 & 2,240 & 2,139 & 1,245 & 858 & 1,324 & 1,719 & 639 & 1,552 & 2,308 & 1,948 \\
\hline Santa Cruz & 356 & 372 & 448 & 834 & 897 & 1,676 & 352 & 473 & 668 & 69 & 556 & 815 & 699 \\
\hline Tierra del Fuego & $\mathrm{ND}$ & 118 & 167 & 195 & 188 & 83 & 207 & 144 & 196 & 19 & 141 & 261 & 244 \\
\hline Total & 212,615 & 211,112 & 210,735 & 218,518 & 231,167 & 109,488 & 113,104 & 113,686 & 156,806 & 42,821 & 67,800 & 68,609 & 80,068 \\
\hline
\end{tabular}

* ND = not done. 